\title{
doispontos:
}

\section{O fim da arte no Modernismo de Mário de Andrade}

\author{
Pedro Duarte \\ Professor Doutor de Filosofia na PUC-Rio. É autor de Estio do tempo: Romantismo e estética moderna (Zahar), A \\ palavra modernista: vanguarda e manifesto (Casa da Palavra), Tropicália ou Panis et circencis (Cobogó). \\ p.d.andrade@gmail.com
}

\begin{abstract}
Resumo: O artigo analisa como o diagnóstico feito pela filosofia de Hegel no século XIX sobre o fim da arte é encontrado ainda no pensamento estético do crítico e escritor modernista Mário de Andrade no século XX, no Brasil. Sem ter se detido na análise do filósofo alemão, Mário contudo preocupou-se com a perda do antigo sentido social da arte, pois ela afastaria o Modernismo da pretensão de servir de esteio para a formação do Brasil. Os anos heroicos de 1920 da vanguarda brasileira cederam espaço, desde a década de 1930, para a autocrítica sobre o individualismo e o formalismo da arte moderna. Este artigo sustenta a tese de que tal autocrítica tardia de Mário de Andrade ao Modernismo deveu-se à tomada de consciência sobre o que, segundo a estética de Hegel, chamamos de fim da arte. Palavras-chave: Modernismo, individualismo, formalismo, arte, Hegel, Mário de Andrade.
\end{abstract}

\section{The End of Art in Mario de Andrade's Modernism}

\begin{abstract}
The article approaches how the diagnosis made by the philosophy of Hegel in the $19^{\text {th }}$ century about the end of art is still found in the aesthetic thinking of the modernist critic and writer Mário de Andrade in the $20^{\text {th }}$ century in Brazil. Without dealing with the analysis of the German philosopher itself, Mário nevertheless worried about the loss of the old social meaning of art, since it would take away from Modernism the pretension of serving as a mainstay for the formation of Brazil. The 1920s heroic years of the Brazilian avant-garde have given way, since the 1930s, to self-criticism over individualism and formalism of modern art. This article supports the thesis that this late self-criticism of Mário de Andrade to Modernism was due to the awareness of what, according to Hegel's aesthetics, we call the end of art.
\end{abstract}

Key-words: Modernism, individualism, formalism, art, Hegel, Mário de Andrade.

O tema do fim da arte parece não ter fim. Desde que Hegel, em seus Cursos de estética no século XIX, percebeu que os momentos de ouro da arte grega e mesmo da Idade Média tinham ficado no passado, a questão tornou-se premente. Não é segredo que, quando o filósofo proferiu tal diagnóstico, estava distante de pretender enunciar que, durante a sua época, as obras de arte deixariam de ser produzidas. Pelo contrário, Hegel tinha plena consciência de que grandes artistas estavam trabalhando, enquanto ele filosofava. Lembre-se que a sua época era também a de Goethe. O que terminara, para ele, era um período histórico clássico em que a arte desempenhava papel central para a existência coletiva da sociedade. Essa força pública da arte, que a atrelava por vezes à religião, transformara-se em deleite privado na época moderna. Não por mero acaso, Hegel foi contemporâneo da consolidação dos primeiros grandes museus, que significava um processo de retirada das obras de sua inserção no cotidiano social das comunidades para dar a elas um espaço autônomo. Saíam da vida comum. 
Essa origem da discussão sobre o fim da arte pode ser precisamente situada na introdução dos Cursos de estética de Hegel, publicados após sua morte em 1835, com a organização de Gustav Hotho, a partir de anotações dos alunos e de um manuscrito hoje perdido do autor. $\mathrm{O}$ destino do que começava ali, entretanto, é menos nítido. Não porque dificilmente ouvimos os seus ecos, e sim porque para onde quer que as nossas orelhas estejam viradas é possível escutá-los. Entre os maiores filósofos e críticos de arte, há autores que trataram explicitamente do tema no século XX: Martin Heidegger e Giulio Carlo Argan são exemplares. Hans Belting discutiu o fim da história da arte e Arthur Danto o que ficaria após o fim da arte. Em sua teoria estética, Theodor Adorno admitiu que, agora, a única coisa evidente sobre a arte era que nada mais era evidente. Não só teóricos debateram o tema, entretanto, mas também artistas. O principal foi o artista conceitual Joseph Kosuth. No fim dos anos 1960, Hélio Oiticica discutia ainda a anti-arte no Brasil. Essa lista poderia se multiplicar, conforme verificamos pelo livro Teoria do fim da arte, de Pedro Süssekind ${ }^{1}$, que relata diversas leituras feitas a partir da ideia original de Hegel. Logo, a dificuldade com o tema do fim da arte não está na falta de interpretações a seu respeito, e sim no excesso.

Em cada interpretação, o diagnóstico de Hegel ganha uma inflexão específica, um ou outro aspecto seu é acentuado. Nunca se ignora, contudo, que o significado da tese era fundamentalmente histórico. Rigorosamente, Hegel estava defendendo que "a arte não mais proporciona aquela satisfação das necessidades espirituais que épocas e povos do passado nela procuravam e só nela encontraram"2. Sublinhe-se o "não mais" pois ele é a cifra da historicidade da tese de Hegel, que marca um antes e um depois, a antiguidade e a modernidade. Semelhante partição histórica está presente nas análises de um autor que, a despeito dos tantos que se debruçaram sobre o tema do fim da arte, raramente foi atrelado a ele. É o pensador, crítico, poeta e escritor brasileiro Mário de Andrade, que desenvolveu a sua obra no Modernismo, na primeira metade do século XX. Embora não se refira explicitamente a Hegel ou se empenhe no comentário sobre a doutrina do filósofo alemão, Mário elaborou especialmente na parte mais tardia de sua obra, na década de 1930 - uma perspectiva histórica sobre a arte no Ocidente cuja ideia essencial diz respeito ao fim de sua importância comunitária na época moderna. Cerca de um século após a morte de Hegel, seu diagnóstico sobre a transformação da arte ainda tinha pertinência para pensar criticamente qual seria o papel que a produção cultural desempenharia no Brasil do século XX, como demonstram ensaios de Mário de Andrade, por exemplo, "O artista e o artesão" e "O movimento modernista".

Mário, entretanto, é conhecido primeiro pela atitude vanguardista que marcou sua produção desde a década de 1920. O conjunto de poemas de Pauliceia desvairada teve um impacto decisivo na ruptura da literatura brasileira com a tradição parnasiana, pois trazia versos livres descrevendo uma paisagem urbana, diferentemente das rimas e métricas ambientadas na natureza que permaneciam nas letras nacionais. Sem ele, é difícil imaginar que livros como Alguma poesia, de Carlos Drummond de Andrade, e Libertinagem, de Manuel Bandeira, fossem escritos e publicados já em 1930. Lendo a extraordinária correspondência que Mário manteve com ambos, fica evidente a função formadora que ele teve sobre o jovem e o amigo. Não é, porém, só esse vanguardismo estético que orienta Mário. Volumes posteriores de poemas, como Clã do Jabuti, são indicadores de que a liberdade estética estava atrelada a um projeto de país, que seria fundamentado na cultura. O retrato do Brasil que o autor procurou fazer apareceu no romance Macunaíma, em 1928. Seus artigos de crítica apontavam a mesma direção: o vínculo entre arte e sociedade deveria dar esteio para uma ideia de Brasil. Esses anos heroicos do Modernismo nacional parecem desconhecer por completo o problema do fim da arte. Ela seria expressão do sentimento comunitário do Brasil.

Brasil...

Mastigado na gostosura quente de amendoim...

Falado numa língua curumim

De palavras incertas num remeleixo melado melancólico...

Saem lentas frescas trituradas pelos meus dentes bons...

Molham meus beiços que dão beijos alastrados

E depois remurmuram sem malícia as rezas bem nascidas... 
Brasil amado não porque seja minha pátria,

Pátria é acaso de migrações e do pão-nosso onde Deus der...

Brasil que eu amo porque é o ritmo do meu braço aventuroso,

O gosto dos meus descansos,

$\mathrm{O}$ balanço das minhas cantigas amores e danças.

Brasil que eu sou porque é a minha expressão muito engraçada,

Porque é o meu sentimento pachorrento,

Porque é o meu jeito de ganhar dinheiro, de comer e de dormir. ${ }^{3}$

Nestes versos de "O poeta come amendoim”, alguns dos mais belos que Mário escreveu, o Brasil aparece não como ente abstrato ou signo nacionalista, mas como o sentimento íntimo que une os seus habitantes. É em um ato cotidiano e simples, como o de comer, que se encontra o Brasil, pois ele está presente igualmente entre pobres e ricos, negros e brancos, mulheres e homens, crianças e adultos... Os poetas escrevem mas também comem amendoim, como todo mundo. Cabe a eles, entretanto, expressar artisticamente como tal ato trivial pode ser revelador da brasilidade. Não há ufanismo. Não há superioridade do Brasil. Há apenas este "jeito". O Brasil é um jeito de ganhar dinheiro, comer, dormir. Nas palavras do poeta, este jeito é nomeado e pode funcionar como reconhecimento mútuo de pertencimento comunitário. É a arte que conferiria à pátria um sentido interno para os que nela estão.

Havia no Modernismo, portanto, a pretensão de interferir na formação do país através da arte. Em um dos prefácios - não publicado originalmente - para a rapsódia Macunaíma, Mário anunciava como concebera a comparação do protagonista, "herói da nossa gente", com o Brasil. O personagem brinca, diverte e ri, mas também mente, engana e manipula. Representaria o país especialmente pela sua falta de caráter, que é entendida por Mário tanto em um sentido moral quanto ontológico. Faltaria a ele uma característica definida de vez. Macunaíma e o Brasil não estariam ainda formados. O brasileiro "está que nem o rapaz de vinte anos: a gente mais ou menos pode perceber tendências gerais, mas, ainda não é tempo de afirmar coisa nenhuma" ${ }^{4}$, escrevia. Essa abertura presente do ser brasileiro deveria receber depois uma direção futura, definida pela arte. Dela viria o sentimento nacional comum, amparado na vocação popular do folclore, justamente onde Mário buscou elementos para compor o seu Macunaíma.

Esse projeto modernista de Brasil, de que aqui só pude grosseiramente esboçar o sentido geral, foi a convicção que moveu a vida e a obra de Mário. Durante os anos 1920, deu animação e energia ao autor. Mais tarde, na década de 1930, foi o objeto de sua frustração e, por consequência, de veemente autocrítica. Há inúmeras maneiras de interpretar essa mudança de apreciação teórica e de tom emocional de Mário diante do Brasil e da arte moderna, desde as mais filosóficas até as mais biográficas. Eu gostaria de sugerir aqui, pendendo mais para as primeiras hipóteses e não para as últimas, que Mário deu-se conta, entre o final dos anos 1920 e o começo dos anos 1930, de alguma coisa de que talvez sempre desconfiasse mas que até ali não conseguira assumir: o fim da arte. Isso tinha, para ele, um significado histórico semelhante ao que originalmente lhe emprestara Hegel: término de uma época na qual a expressão artística era mais do que a manifestação criativa de um só indivíduo em suas obras, época na qual o artista era reflexo de uma comunidade inteira, à qual pertencia e estava ligado. Note-se que, para Mário então, o endosso dessa tese não era matéria erudita, não era só um estudo. Ela tinha consequências práticas e existenciais decisivas para tudo aquilo no que a sua obra estivera empenhada por mais de uma década. Se a arte moderna distanciara-se da sociedade, como é que o Modernismo capitaneado por Mário poderia contribuir para um processo de formação do sentimento comunitário de nação brasileira?

"O meu passado não é mais meu companheiro", escreveu Mário em 1942, "eu desconfio do meu passado"5. Essa dramática declaração foi feita em público, em uma conferência que marcava a celebração das duas décadas da Semana de Arte Moderna de 1922 realizada no Teatro Municipal de São Paulo, evento mais famoso de todas as movimentações modernistas no Brasil. $\mathrm{O}$ tom festivo que ronda comemorações desse 
tipo, contudo, estava ausente das palavras do autor. Na conferência, intitulada por ele de "O movimento modernista”, o balanço do que ficara para trás dá lugar, sobretudo no fim, à confissão dolorosa de que, a despeito de tudo que foi conquistado para a arte e o Brasil, o principal tinha ficado faltando: mudar a vida. Nos termos de Mário, o seu Modernismo tinha alcançado "o direito permanente à pesquisa estética", ou seja, uma liberdade para o artista arriscar formas inovadoras de linguagem em seu meio sem um aprisionamento acadêmico inofensivo; e também "a estabilização de uma consciência criadora nacional", ou seja, a incorporação do dados brasileiros na produção artística do país, sem preconceitos colonizados. Se esses dois objetivos modernistas, contudo, tinham sido alcançados, já o terceiro - e mais importante não. Era a "atualização da inteligência brasileira", ou seja, o seu interesse social' .

O argumento de Mário, em 1942, era que "a inteligência estética se manifesta por intermédio de uma expressão interessada da sociedade, que é a arte" . Os filósofos sabem que essa nomenclatura evoca, ainda que a contrapelo, a doutrina de Immanuel Kant, desenvolvida no fim do século XVIII, para a qual a atitude desinteressada seria a condição número um da experiência estética. $O$ pensador alemão defendia que, para o prazer puramente estético ocorrer, era preciso que estivéssemos despreocupados de qualquer outro interesse: cognitivo, moral, social ou político. Não fosse assim, o que a beleza proporciona ficaria bloqueado para nós, na medida em que exigiríamos outra qualidade - que não a própria beleza - de um objeto. Isso significava, para Kant, que o gosto seria a faculdade na qual o prazer estético é independente de todo o interesse ${ }^{8}$. No entanto, Mário exigia precisamente que a arte fosse uma expressão interessada da sociedade, opondo-se assim, se não a Kant diretamente, pelo menos aos kantianos que constituíram uma tradição que reivindica a total independência da arte em relação a outros interesses que compõem a vida social. Essa tradição identificou - e nisso Kant talvez não a referendasse, como observou, com toda razão, Heidegger mais tarde ${ }^{9}$ - a condição desinteressada à simples indiferença. É a ela que Mário se opõe, na medida em que ele demanda da arte ser afetada pela sociedade e responda a ela, preservando o vínculo entre a experiência estética individual e a comunidade geral.

Nesse sentido, o belo era um valor a ser discutido, e não um signo absoluto do que a arte deve produzir. É que a beleza, pensava Mário, designou na época moderna a procura autossuficiente de um prazer individualista. Neste aspecto, não apenas podia como devia ser criticada. Pois a expressão interessada da sociedade "tem uma função humana, imediatista e maior que a criação hedonista da beleza" ${ }^{10}$, escreveu. $\mathrm{Ou}$ seja, o desinteresse na experiência da beleza deveria ser abandonado, em nome da arte que se envolve com a comunidade. No caso da conferência de Mário, esse imperativo daria vazão a uma retrospectiva arrasadora do Modernismo e de sua obra. "Eu que sempre me pensei, me senti mesmo, sadiamente banhado de amor humano, chego no declínio da vida à convicção de que faltou humanidade em mim" ${ }^{11}$, dizia ele. Talvez haja, em toda a visão tardia de Mário sobre seu próprio Modernismo, certo exagero oriundo de sua formação cristã, afeita à culpa, pois várias vezes o prazer no qual os anos heroicos do movimento foram vividos é repudiado. Parece até que a felicidade pessoal era um defeito, bem como a "festa em que vivíamos"12. Isso não invalida, porém, o que há de verificação corajosa do legado do movimento pelo seu maior líder.

O engano é que nos pusemos combatendo lençóis superficiais de fantasmas. Deveríamos ter inundado a caducidade utilitária de nosso discurso, de maior angústia do tempo, de maior revolta contra a vida como está. Em vez: fomos quebrar vidros de janelas, discutir modas de passeio, ou cutucar os valores eternos, ou saciar nossa curiosidade na cultura. E se agora percorro a minha obra já numerosa e que representa uma vida trabalhada, não me vejo uma só vez pegar a máscara do tempo e esbofeteá-la como ela merece. Quando muito lhe fiz de longe umas caretas. Mas isto, a mim, não me satisfaz. ${ }^{13}$

O peso pessoal que tem o depoimento de Mário em 1942 na conferência sobre "O movimento modernista" pode dar uma impressão de que se trata somente de uma crise individual do autor com a herança da vanguarda por ele encampada. Sem deixar de ser isso também, o que ali se concluía, contudo, 
era um processo teórico de revisão crítica de Mário sobre o Modernismo a partir do exame histórico das transformações da arte ocidental na sua contemporaneidade. Esse processo teve sua cristalização mais contundente, como percebeu Eduardo Jardim em Limites do moderno: o pensamento estético de Mário de Andrade ${ }^{14}$, na aula inaugural que o autor proferiu em 1938 para o curso de História e Filosofia da Arte da Universidade do Distrito Federal, no Rio de Janeiro - depois publicada no livro O baile das quatro artes, com o título "O artista e o artesão". É aí que está a versão de Mário para o fim da arte: a ideia de que ela teria se perdido de sua vocação original - servir de fundamento para a comunidade - desde o Renascimento, tornando-se o reino da busca pela pura beleza em si. Os fundamentos teóricos mais gerais da autocrítica ao Modernismo que Mário faria em 1942, portanto, podem ser encontrados nesta aula ainda de 1938.

Em "O artista e o artesão", Mário estabelece uma cronologia para o fim da arte que começaria com o Renascimento, consolidar-se-ia no Romantismo e subordinaria a Modernidade daí em diante. Isso quer dizer que, a partir então, a arte teria se perdido de sua vocação social original, fazendo do encantamento da beleza uma finalidade das obras. O vínculo com a sociedade deixava de ser o fim da arte e por isso ela chegava ao fim, ou seja, quando a arte se perde de seu fim como função, ela encontra o seu fim como término. Isso estaria ocorrendo na época moderna, de acordo com Mário. O seu subjetivismo generalizado teria feito, na estética, o artista mergulhar dentro de si, em vez de permanecer ligado à sua comunidade. Resumindo a argumentação, a pesquisa experimental moderna - e modernista - teria sedimentado dois aspectos que vitimam a arte: de um lado, o individualismo do artista; e, de outro, o formalismo da obra. Não haveria, assim, mais a associação coletiva da arte com seu mundo. Seria dentro desse contexto que, mesmo inconscientemente, a vanguarda brasileira estaria situada.

O individualismo seria causado pela inflação do ego dos artistas, superando a própria obra a serviço da qual ele deveria estar. Seria uma atitude sentimental, na qual a obra de arte é engolfada pelo eu. O espírito "vaidoso de sua vontadinhas" nem mais respeitaria a matéria resistente da natureza. Daí que a consequência do individualismo seja o formalismo: o sujeito imporia a forma que bem quer à obra, sem que a matéria desempenhe um papel relevante neste processo. $\mathrm{O}$ artista moderno teria se perdido das exigências materiais, que os artesãos conhecem tão bem pois são comprometidos com uma fabricação na qual a beleza por si mesma vale pouco. $\mathrm{O}$ objeto que eles fazem é útil, sua forma precisa estar adequada a esta finalidade. Isso restringiria a liberdade do sujeito, positivamente. Um sapato, por sua função de calçar, já determina quais são os materiais que podem ou não o constituir, bem com sua forma geral. O óleo, o lápis, a pedra, o som, a palavra, a tela, o pincel e o camartelo têm as suas leis, defendia Mário. Mesmo quando flexíveis, elas deveriam condicionar nosso espírito. "Se o espírito não tem limites na criação, a matéria o limita na criatura" 15 , sentenciou ele. O lado artesão era, assim, justamente o que estaria faltando ao artista na época moderna, essa espécie de humildade do sujeito diante do objeto e da forma diante da matéria. Sem isso, o elo do artista com seu entorno provavelmente se romperia de uma vez por todas.

Existiriam, em tese, três elementos de que precisa qualquer artista: a técnica, a virtuosidade e, enfim, o talento. Pelo menos, é assim que Mário define em "O artista e o artesão" ${ }^{\text {" }}$. Técnica diz respeito à habilidade corporal - manual do escultor, vocal do cantor e assim em diante - no domínio de seu material, por exemplo a pedra ou a voz. Virtuosidade diz respeito ao conhecimento histórico das várias soluções que, desde os mestres do passado, foram encontradas para problemas típicos desta ou daquela arte, ou seja, versa sobre um saber prático oriundo da tradição, por exemplo na construção pictórica da perspectiva. Talento, por seu turno, diz respeito àquele "não sei o quê" de cada um graças ao qual a poesia penetra em qualquer obra, a genialidade inexplicável. Historicamente, a tese de Mário é que a dimensão técnica do artesanato foi perdendo importância, enquanto o talento predominou. O resultado moderno é o desequilíbrio: os artistas são - e se acham - muito talentosos, mas falta a eles o aprendizado técnico, sem o qual a sua genialidade é simplesmente desperdiçada, 
pois não se transforma em obra bem definida no mundo. $\mathrm{O}$ "artista que não seja ao mesmo tempo artesão, quero dizer, artista que não conheça perfeitamente os processos, as exigências, os segredos do material que vai mover, não é que não possa ser artista", escrevia Mário, "mas não pode fazer obras de arte dignas do nome" ${ }^{17}$.

Nesse sentido, o pensamento estético de Mário recomenda uma contenção ou uma economia formal por parte do artista. Isso daria um equilíbrio à arte entre dois de seus elementos: a técnica e o talento. São os dois elementos essenciais, de acordo com Mário, pois a virtuosidade, embora possa contribuir muito para o artista, é um atributo dispensável. O exemplo perfeito desse equilíbrio entre uma genialidade individual que dá forma à obra e uma humildade artesanal que adere a seus materiais seria - segundo lemos não em "O artista e o artesão", e sim em Aspectos das artes plásticas no Brasil - o Aleijadinho. Nele, a arte toda se ajustaria, sem tirar nem pôr. "Ele foi um técnico formidável que sabia perfeitamente se condicionar aos materiais que empregava, bem como até que ponto os podia condicionar à sua imaginação expressiva" ${ }^{18}$. Justamente essa combinação que tinha a obra do arquiteto e escultor mineiro do século XVIII era o que faltaria à arte moderna e, em grande medida, modernista que o próprio Mário e seus amigos estariam praticando nos anos 1920. Nesta arte, a fantasia subjetiva estaria se sobrepondo ao condicionamento material, e o preço desse desajuste eram as obras sem lastro social, meros produtos individualistas e formalistas do artista. Com isso, a arte teria degringolado historicamente. Toda a argumentação de "O artista e o artesão" pode assim encontrar, como contraponto exemplar à crítica ali feita da arte moderna, a consideração sobre o Aleijadinho em Aspectos das artes plásticas no Brasil.

Orgulhoso de si, o artista moderno, com o eu inflado, ignora as limitações que vêm da matéria para a constituição da obra e, com isso, ela perde qualquer dimensão que transcenda o indivíduo que a criou. Logo, a arte é apartada dos outros, distancia-se da sociedade, da coletividade. Deixa de servir ao alto propósito que no passado, em contraposição histórica à arte moderna, tinha na Grécia, de acordo com Mário, quando o indivíduo era ainda pouco ou nada concebido. Sua existência era então indissociável da comunidade. "Com os gregos, já estamos num outro mundo, mais atento às forças da vida terrestre", o que, explicava Mário, "para eles é ainda uma vida de rito, porque profundamente social"19. O problema para a arte moderna estaria na sobreposição do artista em relação à obra: ele passaria a valer mais do que ela. Espacialmente, esta arte abandonou a exterioridade do mundo e passou para a interioridade do sujeito. Não é a obra que conta, como um ajuste equilibrado entre matéria e forma, natureza e homem. $\mathrm{O}$ formalismo da obra, que a distancia da coletividade, é reflexo do individualismo do artista, cuja consequência histórica é o isolamento da arte devotada só ao belo. Não é uma arte panfletária ou engajada que Mário procura, e sim menos individualista, logo, menos elitista. Eis o diagnóstico crítico de "O artista e o artesão" em 1938.

Em diversos outros momentos de sua obra, Mário também manifestou as suas preocupações com a transformação da beleza no fim em si da arte. Desde os primeiros anos da década de 1920, em A escrava que não é Isaura, ele já escrevia que "a beleza não deve ser um fim", que "a beleza é a consequência" e até mesmo, de um ponto de vista histórico, que "nenhuma das grandes obras do passado teve realmente como fim a beleza"20. Embora menos sistematizada, a crítica à procura virtuosística da beleza já estava em curso. $\mathrm{Na}$ arte, um interesse mais amplo é que deve orientar a investigação estética, ficando a beleza apenas como um efeito secundário. Esse interesse era o que, claramente, dirigia as obras ainda na Grécia, por exemplo. Era o interesse social. Isso quer dizer que Mário já abordava a arte como um problema histórico ali. Só que o seu Modernismo, ao contrário do que ocorreria nos anos 1930, ainda era por ele avaliado positivamente, na medida em que trazia valores estéticos distintos da mera beleza. Lá, ele apontava que "o que fez imaginar que éramos, os modernizantes, uns degenerados, amadores da fealdade foi simplesmente um erro tolo de unilateraliazação da beleza" ${ }^{\text {21 }}$. Ou seja, as experiências estéticas estariam ampliando a atuação da arte, para além do conceito clássico e antigo de beleza. Esse era o mérito modernista. No entanto, para a apreciação de Mário anos depois, como fica claro em 
“O movimento modernista”, ele seria insuficiente. Isso diria respeito somente ao direito de pesquisa estética, mas não à atualização da inteligência brasileira para a preocupação social.

Nos anos 1930, consolida-se para Mário a consciência de que o movimento de vanguarda modernista no Brasil situava-se em meio a uma condição histórica que não lhe permitia realizar o que de mais importante ele precisava. Essa consciência assoma definitivamente em 1938, com "O artista e o artesão", sendo que suas consequências mais diretas para o caso brasileiro surgem em 1942, em "O movimento modernista". Na história da filosofia, a condição moderna que Mário tratava poderia ser chamada - tendo em vista a estética de Hegel - de fim da arte. O fim da vocação coletiva da arte era problemático para a pretensão do Modernismo brasileiro, já que ele - ao contrário de vários congêneres, como Construtivismo russo, Expressionismo alemão, Cubismo espanhol, Surrealismo francês - tinha uma preocupação não apenas com a linguagem, mas com a nacionalidade. Para Mário, a arte deveria encontrar suas fontes na cultura popular, sobretudo o folclore, para servir de fundamento da nação, ao seu modo. Isso era justamente o que, na época moderna, estava interditado por conta da privatização individualista da nossa experiência estética, que Hegel previra ainda durante o século XIX. Não haveria mais uma arte propriamente popular, nesse sentido.

No caso de Hegel, contudo, o declínio da arte significava, simultaneamente, a ascensão da filosofia. Sua concepção teleológica da história previa que a humanidade passaria da expressão artística para a filosófica, que o espírito alcançaria assim forma de manifestação mais ampla e profunda da verdade ${ }^{22}$. $\mathrm{O}$ fim da arte atesta o progresso da humanidade: ela superaria a necessidade sensível, atingindo a reflexão pura. Nada disso aparece no pensamento de Mário. Por isso, o sentimento de cada um desses dois autores, bem como o tom de seus textos, ao tratar de um diagnóstico parecido é, ainda assim, muito diferente. O otimismo que as páginas de Hegel exibem diante da história porvir contrastam com a melancolia e o desespero que Mário transmite no fim da vida em "O movimento modernista”. Não havia, para ele, qualquer sentido de progresso no fim da arte, mas apenas insuficiência. Em "O artista e o artesão”, ele ainda considerou que uma atitude estética mais próxima da lida com o material da obra era um caminho para se resgatar a vocação coletiva original da arte. Era 1938. Menos de meia década depois, nem essa possibilidade seria aventada mais.

Na conferência sobre "O movimento modernista”, Mário conclui desistindo da arte. Parecia desacreditar de qualquer sentido humano para ela. Decide, ali, pela saída política. Contemporâneo da Segunda Guerra Mundial e escaldado com o Estado Novo no Brasil, Mário aconselharia a ação direta pela política, e não a produção de objetos pela arte. Sua frustração com o Modernismo o faz dizer que ele e seu grupo deveriam servir de lição, jamais de exemplo. "Si de alguma coisa pode valer o meu desgosto, a insatisfação que eu me acuso, que os outros não se sentem assim na beira do caminho, espiando a multidão passar”, comentava Mário, para convocar a todos que "marchem com as multidões" ${ }^{23}$. Ele mesmo, contudo, não marchou. Não era um homem político, como confessara. Morreria pouco depois, em 1945. Triste. Seu fim confunde-se com o fim da arte, como permitem vislumbrar seus últimos versos. Tem mais não.

\footnotetext{
É noite. E tudo é noite. E o meu coração devastado

É um rumor de germes insalubres pela noite insone e humana.

Meu rio, meu Tietê, onde me levas?

Sarcástico rio que contradizes o curso das águas

$\mathrm{E}$ te afastas do mar e te adentras na terra dos homens,

Onde me queres levar?...

Por que me proíbes assim praias e mar, por que

Me impedes a fama das tempestades do Atlântico

$\mathrm{E}$ os lindos versos que falam em partir e nunca mais voltar?

Rio que fazes terra, húmus da terra, bicho da terra,

Me induzindo com a tua insistência turrona paulista

Para as tempestades humanas da vida, rio, meu rio!...
} 
Já nada me amarga mais a recusa da vitória

Do indivíduo, e de me sentir feliz em mim.

Eu mesmo desisti dessa felicidade deslumbrante,

E fui por tuas águas levado,

A me reconciliar com a dor humana pertinaz,

E a me purificar no barro dos sofrimentos dos homens.

Eu que decido. E eu mesmo me reconstituí árduo na dor

Por minhas mãos, por minhas desvividas mãos, por

Estas minhas próprias mãos que me traem,

Me desgastaram e me dispensaram por todos os descaminhos,

Fazendo de mim uma trama onde a aranha insaciada

Se perdeu em cisco e polem, cadáveres e verdades e ilusões. ${ }^{24}$

\section{NOTAS}

1. Pedro Süssekind, Teoria do fim da arte (Rio de Janeiro: 7Letras, 2017).

2. Hegel, G. W. F. Cursos de estética I (São Paulo: Edusp, 2001), p. 35.

3. Mário de Andrade, “O poeta come amendoim”, in Poesias completas (Belo Horizonte: Villa Rica, 1993), p. 162.

4. Mário de Andrade, "Prefácios para Macunaíma", in Telê Porto Ancona Lopez, Macunaíma: a margem e o texto (São Paulo: Hucitec; Secr. De Cultura, Esporte e Turismo, 1974), p. 289.

5. Mário de Andrade, “O movimento modernista”, in Aspectos da literatura brasileira (São Paulo: Martins, 1974), p. 245.

6. Mário de Andrade, "O movimento modernista”, in Aspectos da literatura brasileira (São Paulo: Martins, 1974), p. 252.

7. Mário de Andrade, “O movimento modernista”, in Aspectos da literatura brasileira (São Paulo: Martins, 1974), p. 252.

8. Immanuel Kant, Crítica da faculdade do juízo (Rio de Janeiro: Forense Universitária, 1995), p. 55.

9. Martin Heidegger, "A doutrina kantiana sobre o belo: sua interpretação equivocada por meio de Schopenhauer e de Nietzsche”, in Nietzsche I (Rio de Janeiro: Forense Universitária, 2007), p. 99.

10. Mário de Andrade, "O movimento modernista”, in Aspectos da literatura brasileira (São Paulo: Martins, 1974), p. 252.

11. Mário de Andrade, "O movimento modernista", in Aspectos da literatura brasileira (São Paulo: Martins, 1974), p. 252.

12. Mário de Andrade, "O movimento modernista”, in Aspectos da literatura brasileira (São Paulo: Martins, 1974), p. 253.

13. Mário de Andrade, "O movimento modernista”, in Aspectos da literatura brasileira (São Paulo: Martins, 1974), p. 253.

14. Eduardo Jardim, Limites do moderno: o pensamento estético de Mário de Andrade (Rio de Janeiro: Relume Dumará, 1999).

15. Mário de Andrade, “O artista e o artesão”, in O baile das quatro artes (São Paulo, Martins, 1963), p. 35.

16. Mário de Andrade, "O artista e o artesão", in O baile das quatro artes (São Paulo, Martins, 1963), p. 14-5.

17. Mário de Andrade, “O artista e o artesão”, in O baile das quatro artes (São Paulo, Martins, 1963), p. 12.

18. Mário de Andrade, Aspectos das artes plásticas no Brasil (Belo Horizonte: Itatiaia, 1984), p. 37. 
19. Mário de Andrade, “O artista e o artesão”, in O baile das quatro artes (São Paulo, Martins, 1963), p. 21.

20. Mário de Andrade, “A escrava que não é Isaura”, in Obra imatura (Rio de Janeiro: Agir, 2009), p. 238.

21. Mário de Andrade, “A escrava que não é Isaura”, in Obra imatura (Rio de Janeiro: Agir, 2009), p. 239.

22. Hegel, G. W. F. Cursos de estética I (São Paulo: Edusp, 2001), p. 34.

23. Mário de Andrade, "O movimento modernista”, in Aspectos da literatura brasileira (São Paulo: Martins, 1974), p. 255.

24. Mário de Andrade, "A meditação sobre o Tietê", in Poesias completas (Belo Horizonte, Villa Rica, 1993), p. 387.

\section{REFERÊNCIAS}

ANDRADE, M. "Prefácios para Macunaíma", in Telê Porto Ancona Lopez, Macunaíma: a margem e o texto, São Paulo: Hucitec; Secr. De Cultura, Esporte e Turismo, 1974.

. Aspectos da literatura brasileira, São Paulo: Martins, 1974.

. O baile das quatro artes, São Paulo, Martins, 1963.

. Obra imatura, Rio de Janeiro: Agir, 2009.

. Poesias completas, Belo Horizonte: Villa Rica, 1993.

HEGEL, G. W. F. Cursos de estética I, São Paulo: Edusp, 2001.

HEIDEGGER, M. Nietzsche I, Rio de Janeiro: Forense Universitária, 2007.

JARDIM, E. Limites do moderno: o pensamento estético de Mário de Andrade, Rio de Janeiro: Relume Dumará, 1999.

KANT, I. Crítica da faculdade do juízo, Rio de Janeiro: Forense Universitária, 1995.

SÜSSEKIND, P. Teoria do fim da arte, Rio de Janeiro: 7Letras, 2017. 